\title{
Laparoscopic and single incision laparoscopic repair of Morgagni hernia in adults
}

\author{
Erişkinlerde laparoskopik ve tek insizyonlu laparoskopik Morgagni herni tamiri

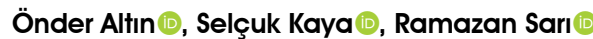 \\ Department of General Surgery, Kartal Dr. Lütfi Kırdar Training and Research Hospital, Istanbul, Turkey
}

\begin{abstract}
Background: In this study, we aimed to compare multiple versus single incision laparoscopic repair of Morgagni hernia in adults and to investigate effectiveness and feasibility of both techniques.

Methods: Between January 2011 and March 2018, a total of 15 patients ( 5 males, 10 females; median age: 58.6 years; range, 36 to 70 years) who underwent laparoscopic or single-incision laparoscopic repair of Morgagni hernia were retrospectively analyzed. Demographic and clinical characteristics of patients, perioperative data, and treatment outcomes were evaluated.
\end{abstract}

Results: The median follow-up was 38 (range, 11 to 84 ) months. Of the patients with Morgagni hernia, 12 were treated with laparoscopic and three were treated with single incision laparoscopic repair technique. Patient satisfaction was excellent for most of the patients in both groups. No recurrence was observed during follow-up.

Conclusion: Morgagni hernia is a very rare type of hernia in adults. Laparoscopic mesh-reinforced primary repair of Morgagni hernia should be one of the first choice in patients, particularly with large hernias that would cause tension on edges of the diaphragm when closed. Single incision laparoscopic repair of Morgagni hernia is also another laparoscopic option with high patient satisfaction.

Keywords: Hernia, laparoscopy, Morgagni, single incision.

Morgagni hernia $(\mathrm{MH})$ is a rare type of congenital diaphragm hernia, which was first described in $1761 .^{[1]}$ Congenital diaphragmatic hernias (CDHs) occur with a failure in the development of muscular structures in diaphragm. Bochdalek hernia is the most common type and $\mathrm{MH}$ constitutes only

\section{$\ddot{O} Z$}

Amaç: Bu çalışmada, erişkinlerde Morgagni hernisinin çoklu veya tek insizyonlu laparoskopik tamiri karşılaştırıldı ve her iki tekniğin etkinliği ve uygulanabilirliği araştırıldı.

Çalışma planı: Ocak 2011 - Mart 2018 tarihleri arasında, Morgagni hernisi nedeniyle laparoskopik veya tek insizyonlu laparoskopik tamir yapılan toplam 15 hasta (5 erkek, 10 kadın; medyan yaş: 58.6; dağ 1 lım, 36-70 yıl) retrospektif olarak incelendi. Hastaların demografik ve klinik özellikleri, perioperatif verileri ve tedavi sonuçları değerlendirildi.

Bulgular: Medyan takip süresi 38 (dağılım, 11-84) ay idi. Morgagni hernili hastaların 12'si laparoskopik ve üçü tek insizyonlu laparoskopik tamir tekniği ile tedavi edildi. Hasta memnuniyeti, her iki grupta da hastaların birçoğunda mükemmel idi. Takip süresince nüks izlenmedi.

Sonuç: Morgagni hernisi erişkinlerde çok nadir görülen bir fıtık türüdür. Morgagni hernisinin laparoskopik meş takviyeli primer onarımı, özellikle primer onarıldığında diyafram kenarlarında gerilime neden olacak kadar büyük fıtığı olan hastalarda ilk tercihlerden biri olmalıdır. Morgagni hernisinin tek insizyonlu laparoskopik tamiri, yüksek hasta memnuniyeti ile diğer bir tedavi seçeneğidir.

Anahtar sözcükler: Herni, laparoskopi, Morgagni, tek insizyon.

3 to $5 \%$ of all $\mathrm{CDHs} .^{[2]}$ Regarding the congenital structure of disease, most of the patients presents in childhood. Despite the treatment options during childhood, some of patients may be asymptomatic and symptoms may appear during adulthood..$^{[2,3]}$ Pulmonary symptoms, pain, pressure and bowel

Received: October 18, 2020 Accepted: December 13, 2020 Published online: October 20, 2021

Correspondence: Önder Altın, MD. Kartal Dr. Lütfi Kırdar Eğitim ve Araştırma Hastanesi, Genel Cerrahi Kliniği, 34865 Kartal, Istanbul, Türkiye. Tel: +90 216- 4583000 e-mail: dronder38@gmail.com 
obstruction are the most common symptoms. Also, $28 \%$ of patients are asymptomatic and $\mathrm{MH}$ can be diagnosed incidentally. ${ }^{[2]}$

Surgery is the treatment of $\mathrm{MH}$ for both asymptomatic and symptomatic patients. It can be implemented via transthoracic and transabdominal techniques. ${ }^{[4,5]}$ To date, there are controversies regarding the surgical techniques to be applied. Some authors recommend transthoracic, ${ }^{[4]}$ while some others recommend transabdominal, thoracoscopic, and laparoscopic techniques. ${ }^{[5-7]}$ With the advancement of technology, minimally invasive surgery has become widely used. Early discharge, less pain, and better results of recovery of minimally invasive surgery are the main advantages compared to open surgery. ${ }^{[7]}$ Laparoscopic repair is the choice of the treatment for the majority of cases in the literature. ${ }^{[8,9]}$ Advantages of laparoscopy are lower complication risk, early discharge from hospital, ${ }^{[7]}$ direct visualization of hernia contents, particularly in emergency cases, easier reduction of hernia contents, less postoperative pain, and better cosmetic results. ${ }^{[10]}$ Disadvantages of laparoscopy are dissection of pleural adhesions and difficulty to retract liver and dense adhesions due to previous abdominal surgeries. ${ }^{[11]}$

Although some of the pediatric patients are treated with single incision laparoscopic surgery, the data for adult patients are still limited.$^{[12]}$ Depending on the rare appearance of disease there are only few case series in the literature, and most of the data consist of case reports. In the present study, we aimed to compare multiple versus single incision laparoscopic repair of $\mathrm{MH}$ in adults and to investigate their effectiveness and feasibility.

\section{PATIENTS AND METHODS}

This single-center, retrospective study was conducted at Kartal Dr. Lütfi Kurdar Training and Research Hospital, Department of General Surgery between January 2011 and March 2018. A total of 15 patients (5 males, 10 females; median age: 58.6 years; range, 36 to 70 years) who underwent laparoscopic repair of MH (LRMH) or single-incision laparoscopic repair of MH (SILMH) were included. All the operations were performed by a single surgeon in our clinic. Data of the patients were retrieved from the hospital database and included patient characteristics and demographics, symptoms, number of previous abdominal operations, contents of hernia sac, side of hernia, defect size, mesh size, operative time, length of hospital stay, complications, follow-up time, and satisfaction of patient. A written informed consent was obtained from each patient. The study protocol was approved by the Kartal Dr. Lütfi Kırdar Training and Research Hospital Ethics Committee (No: 2019/514/167/24). The study was conducted in accordance with the principles of the Declaration of Helsinki.

\section{Surgical procedure}

During surgery, the patients were positioned in reverse Trendelenburg position, the head end of the patient raised to $30^{\circ}$ with right arm tucked and surgeon was standing between patient's leg. An orogastric tube was inserted following anesthesia induction. The first port was inserted just above the umbilicus using closed approach. Pneumoperitoneum was created following the insertion of first port. Two additional ports were placed on both midclavicular lines just above optical port to form a triangle. All the LRMH operations were performed with three ports, and a 30-degree laparoscope was used. Only one of the patients needed an additional port to retract colon and fourth port was inserted on left anterior axillary line on a level with working ports. The SILMH was performed with the SILS ${ }^{\mathrm{TM}}$ Port (Covidien, Mansfield MA, USA). The port was inserted into umbilicus, and rotating instruments were used for manipulation. Patient preparation and surgeon position were the same as LRMH.

Contents of the hernia were reduced following an exploration of the abdomen; a combination of sharp and blunt dissection with gentle traction was performed. The Harmonic ${ }^{\circledR}$ scalpel (Ethicon Inc., Somerville, NJ, USA) was used for omentectomy, when necessary. The hernia sac was not resected and the defect was closed with separate transabdominal sutures using number 0 polypropylene sutures with flattened needle. The Ventralight ${ }^{\mathrm{TM}}$ ST (Bard Davol Inc., Warwick, RI, USA) mesh was used in eight and the Physiomesh ${ }^{\mathrm{TM}}$ (Ethicon Inc., Somerville, NJ, USA) in seven patients. Although, the closest available size was used for large defects, the mesh was shaped for smaller defects to avoid unnecessary use. Following the closure, the mesh was positioned, and absorbable tacks (AbsorbaTack ${ }^{\mathrm{TM}}$, Covidien, Mansfield, MA, USA) were used to fix the mesh in appropriate cases. Intra-corporeal polypropylene sutures were used to fix the mesh in case of pericardial contiguity.

\section{Postoperative follow-up}

All patients were examined with plain chest roentgenogram in the operating room following the operation to exclude complications. Sample images including all steps of a case are presented in Figure 1. All cases were controlled on Days 5 and 10 and at one 

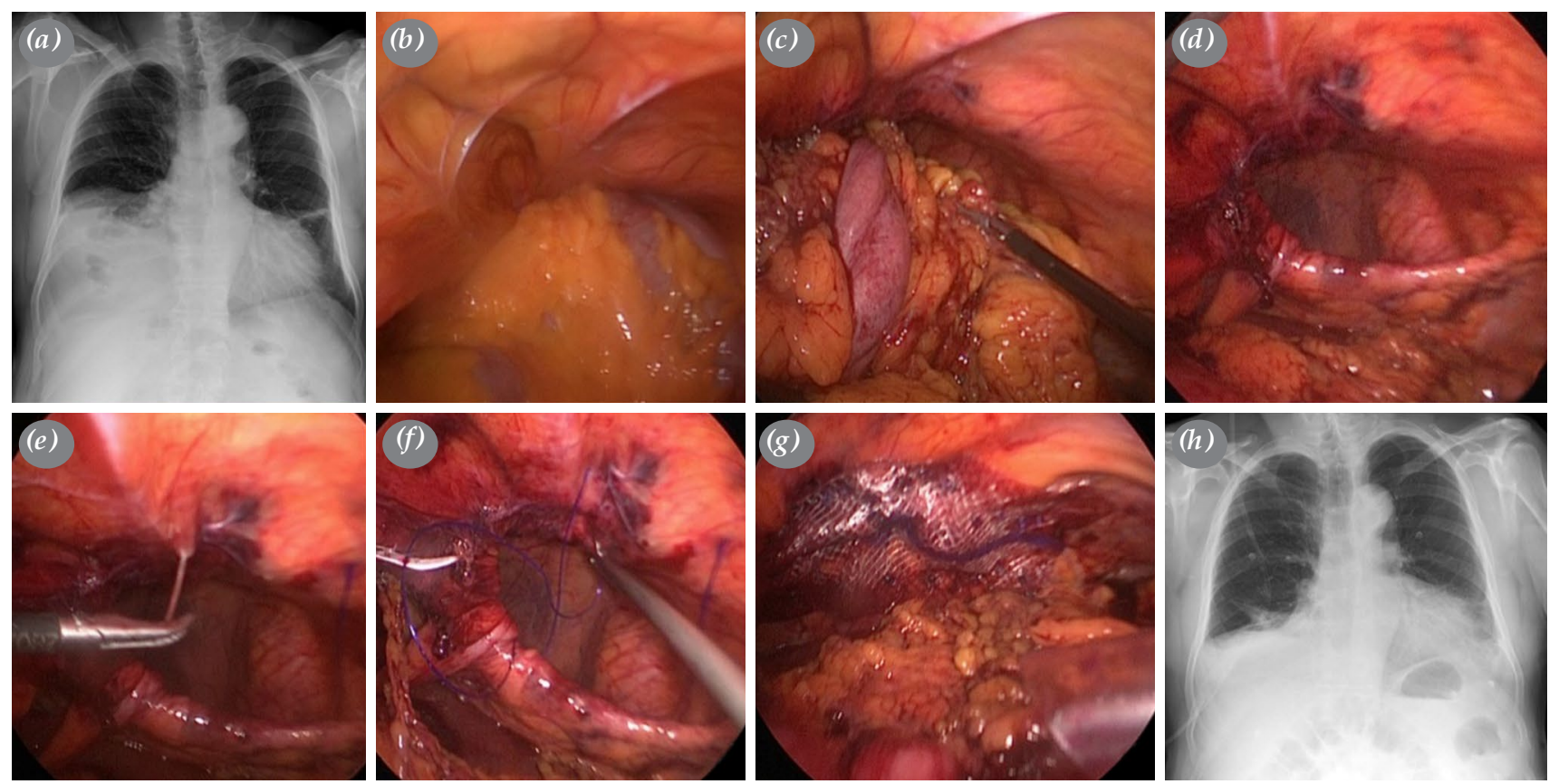

Figure 1. (a) Plain chest X-ray before operation. (b) Contents of the hernia. (c) Reducing the contents of the hernia. (d) Appearance of the hernia following reduction. (e, f) Closure of the defect with transabdominal sutures. (g) Appearance following closure and mesh fixation. (h) Plain chest X-ray roentgenogram after operation.

month and one year. Follow-up controls were carried out by phone calls.

A five-point scale ranging from 1 indicating "worse" to 5 indicating "excellent" was applied to evaluate patient satisfaction of health status following surgery on postoperative Day 30 .

\section{Statistical analysis}

Statistical analysis was performed using the IBM SPSS version 21.0 software (IBM Corp., Armonk, NY, USA). Descriptive data were expressed in mean \pm standard deviation (SD), median (minmax) or number and frequency, where applicable. The Student t-test was used to analyze parametric variables. A $p$ value of $<0.05$ was considered statistically significant.

\section{RESULTS}

Of a total of 15 patients, 12 underwent LRMH and three underwent SILMH. Most of the hernias were right-sided and found in $13(86.7 \%)$ patients, while two (13.3\%) patients had left-sided hernia. The most common type of symptom was dyspnea which increased in recent months and it was found in nine $(60 \%)$ of the patients with multiple symptoms such as cough or epigastric pain. Two (13\%) patients underwent emergency surgery due to acute mechanical intestinal obstruction (AMIO). Four (26.6\%) patients had previous surgery: two (13\%) had appendectomy and two (13\%) had umbilical hernia repair. All patients had a hernia content of omentum (100\%), three patients $(20 \%)$ had transvers colon, and two patients $(13 \%)$ had small intestines inside the sac. Although the patients with a content of colon or small intestines had AMIO, there was no sign of ischemia or necrosis and reduction of bowel was sufficient. The largest hernia defect size was measured as $6 \times 5 \mathrm{~cm}$ in diameter. The largest mesh was $10 \times 15 \mathrm{~cm}$ in diameter. The median operation duration was 69.8 (range, 48 to 82 ) $\mathrm{min}$. There was no conversion to laparotomy in our series.

In our study, we encountered three postoperative complications. One (6.6\%) patient had hematoma on right port site, stitches of port site were removed on postoperative Day 2 and the patient was followed with dressings without any intervention. Hematoma was resolved uneventfully on postoperative Day 15 . One patient $(6.6 \%)$ who had seroma complication on the camera port site was discharged on postoperative Day 3. Seroma was drained with needle injection and healed uneventfully on postoperative Day 12. The other patient had seroma in the hernia sac which was detected on chest X-ray on postoperative Day 2 and started Triflow respiratory exerciser at the same day. The patient who had hernia sac seroma was followed 


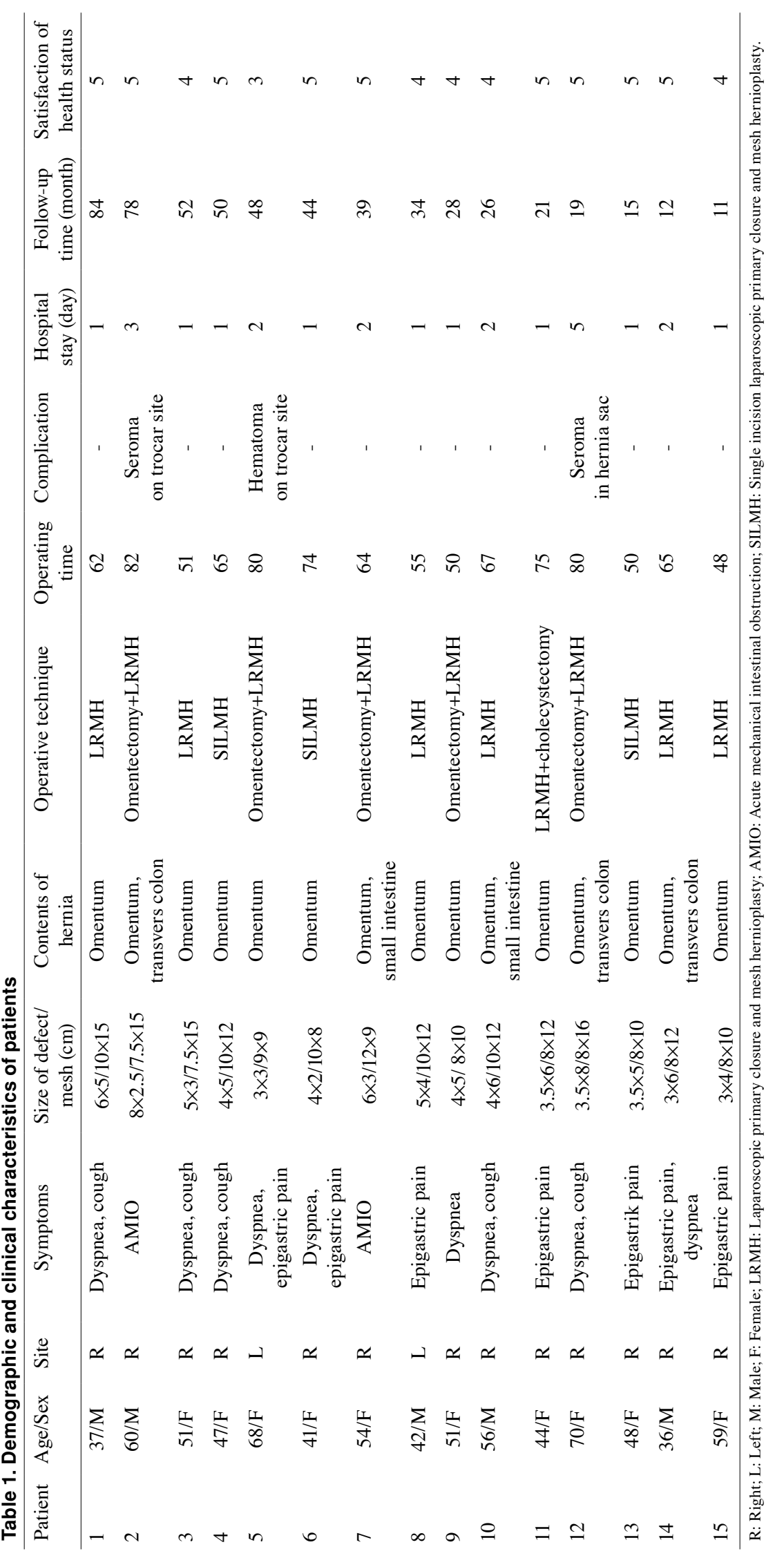


without any invasive intervention and discharged from hospital on postoperative Day 5. The median length of hospital stay was 1.67 (range, 1 to 5) days. Most of the patients considered the operation as "excellent" for satisfaction in both groups. The mean value of satisfaction score was $4.40 \pm 0.49$ for LRMH and 5.0 for SILMH. Although patient satisfaction was excellent for all SILMH patients, the number of patients were inadequate to compare effectively. The median follow-up was 38 (range, 11 to 84) months and no recurrence were observed during the follow-up period. Clinical and demographic data of the patients are presented in detail in Table 1.

\section{DISCUSSION}

Morgagni hernia is a rare type of congenital diaphragm hernia, which was first described by Giovanni Battista Morgagni, an Italian anatomist, in $1761 .^{[1]}$ It constitutes 3 to $5 \%$ of all diaphragmatic hernias and localized posterior to the sternum. ${ }^{[3]}$ McBride and Beasley ${ }^{[13]}$ reported MHs more common in males in childhood, while these hernias were more common in females in adulthood. Ulas et al. ${ }^{[7]}$ found that incidence of female patients with $\mathrm{MH}$ was $66.6 \%$ and the mean age was $56.5 \pm 14.9$ years in their study. In this study, we found similar results to Ulas et al.'s ${ }^{[7]}$ study in terms of sex and age incidence.

The majority of MHs are located on the right side, Arikan et al. ${ }^{[10]}$ found 19 of 21 patients $(90.5 \%)$ on the right side and $9.5 \%$ on the left side. In a study of 18 patients, $89 \%$ of hernias were right-sided, $5.5 \%$ were left-sided, and $5.5 \%$ were bilateral. ${ }^{[14]}$ In this study, we found similar results: $87 \%$ (13/15) of MHs were located on the right side, and left-sided hernias were seen only in two patients.

Patients who are diagnosed incidentally are usually asymptomatic. ${ }^{[15]}$ Adult patients may present with dyspnea, non-specific chest pain, and abdominal pain. Due to the obstruction and strangulation, acute abdominal symptoms are seen in a few number of patients. ${ }^{[16]}$ In the study of Ulas et al., ${ }^{[7]}$ all patients had non-specific symptoms and the incidence of respiratory symptoms was $50 \%$. Most common type of symptom in this study was dyspnea and it was found in nine $(60 \%)$ of the patients with multiple symptoms such as cough or epigastric pain. In addition, epigastric pain (7/15) was the most common gastrointestinal symptom. Two patients presented with AMIO symptoms and admitted to emergency surgery service due to abdominal pain with an increasing severity in recent days, nausea vomiting, loss of fecal, and gas discharge.
Intraoperatively, we encountered omentum in $15(100 \%)$, transverse colon in three (20\%), and small intestine in two (13\%) cases in the hernia sac. The content of hernia sac was omentum and transvers colon in one of two emergency cases, omentum and small intestine in the other patient. We could directly visualize the content of the hernia sac via laparoscopy in these emergency cases, and did not observe any hollow organ necrosis or perforation. In the literature, most of the contents of hernia sac are omentum, transverse colon, small bowel, stomach, and left lobe of liver. ${ }^{[7,14]}$

The main advantages of minimally invasive surgery are early discharge from hospital and better results of recovery. ${ }^{[7]}$ Advantages of transthoracic technique are perfect exposure of hernia sac and provide easy and secure dissection of hernia sac, pleural and pericardial adhesions. In addition, transthoracic technique provides easy surgery in patients with obesity. ${ }^{[14]}$ In emergency surgery, content of hernia sac is not evaluated adequately via transthoracic approach, which is an important disadvantage. ${ }^{[10]}$ Laparoscopic repair is the choice of the treatment for the majority of cases in the literature ${ }^{[8,9]}$ In our study, the patients were treated with LRMH or SILMH. Due to the increased frequency of single incision laparoscopic surgery in daily practice, three patients underwent SILMH. Although there are no definitive indications of SILMH superior to LRMH due to the rarity of $\mathrm{MH}$ in adults, our indication criteria for SILMH were elective surgery, young age due to better cosmetic results, having no obesity (body mass index $\leq 25 \mathrm{~kg} / \mathrm{m}^{2}$ ), small size hernia defect for easy manipulation of instruments, and having no previous abdominal surgery to avoid intraabdominal dense adhesions. Undoubtedly, the cosmetic appearance of a literally "scarless" procedure is one of the main advantages of SILS. A recent study including patients who underwent single-incision endosurgical cholecystectomy showed that the patients had a lower level of postoperative pain and required less analgesics than those who underwent a multiport endoscopic procedure. ${ }^{[17]}$ In the aforementioned study, there was a reduction in the length of hospital stay. On the other hand, there are some disadvantages of SILS. The need for specialized laparoscopic equipment reduces the cost-effectiveness of SILS. Although feasible in experienced hands, the use of conventional laparoscopic instruments in SILS prolongs the operation times and makes the learning curve steeper. As the operation time is reduced with the utilization of specially designed equipment, 
the overall cost of surgery is adversely affected. We believe that longer operation time can be significantly reduced as experience is gained by the operating surgeon and with the use of roticulating instruments. ${ }^{[18,19]}$ Disputes over SILS still exist and mainly focus on the fact that many surgical interventions are much more difficult to perform through a single access site. ${ }^{[20,21]}$

To the best of our knowledge, patients in our series were the first adult cases of SILMH in the literature. We used a simple method, defined by Park and Doyle ${ }^{[12]}$ to close the defect in all cases. The method is applicable with a flattened needle and allows reducing the ports. Although the patients operated with SILMH had a higher mean score than LRMH patients for satisfaction, there needs to be more patients to confirm the advantages of SILMH.

Nearly $95 \%$ of the MHs contain a hernia sac, but the resection of the hernial sac remains controversial. Some authors have suggested the retention of sac to avoid massive pneumomediastinum and injuries to the phrenic nerve. ${ }^{[22]}$ Akbiyik et al. ${ }^{[23]}$ did not remove the hernia sac and there were no complications and recurrence in their study. Ulas et al. ${ }^{[7]}$ also reported that all of the patients in their study had a hernia sac and they resected all the hernia sacs to prevent residual sac and recurrence. Therefore, the issue that needs to be discussed is whether it provides an advantage or not. The common considerations of the opposite situation are the lack of complications and resolution of the symptoms. ${ }^{[24]}$ In our study, we preferred to retain the sac in all patients to avoid pneumothorax and nerve injuries. In our series, we observed pulmonary complication in only one patient due to the hernia sac left in situ. This lung complication was seroma in the hernia sac, and treated with the Triflow respiratory exerciser without any invasive intervention. Although we did not resect the hernia sac, we observed no hernia recurrence during a median of 38 months of follow-up.

In the literature, there is no consensus regarding the repair of hernia defects. Hernia defect can be repaired with a prosthetic mesh, with primary suturing or both techniques. ${ }^{[10]}$ Although most of the cases have been repaired with mesh reinforcement in recent studies, ${ }^{[25]}$ some authors have advocated using primary repair. ${ }^{[7]}$ Kurkcuoglu et al. ${ }^{[11]}$ preferred primary suturing or prosthetic mesh, depending on the size of hernia defect. Although there is an ongoing debate about prosthetic materials, ensuring to support hernia defect with a mesh is the major principle of hernia repair which should be kept in mind. It may not feasible to use a suturing method instead of mesh repair, particularly for the treatment of large diaphragmatic hernia. We believe that the hernia defect should be repaired according to the classical surgical principles and, therefore, we repaired defects with primary suturing and supporting with prosthetic mesh in all patients to prevent recurrence. Based on these findings, we suggest that laparoscopic reinforcement with a mesh to repair $\mathrm{MH}$ is safe and feasible, but primary suturing of defect may be preferred as a safe approach in small-size hernia defects.

The single-center and retrospective design and a relatively small sample size are the main limitations of this study. Further studies are needed to draw firm conclusions on this subject.

In conclusion, Morgagni hernia is a very rare type of hernia in adults. Laparoscopic mesh-reinforced primary repair of Morgagni hernia should be one of the first choice in patients, particularly with large hernias that would cause tension on edges of the diaphragm when closed. Single incision laparoscopic repair of Morgagni hernia is also another laparoscopic option, but further large-scale studies are required to gain a better understanding of its advantages.

\section{Declaration of conflicting interests}

The authors declared no conflicts of interest with respect to the authorship and/or publication of this article.

\section{Funding}

The authors received no financial support for the research and/or authorship of this article.

\section{REFERENCES}

1. Harrington SW. Clinical manifestations and surgical treatment of congenital types of diaphragmatic hernia. Rev Gastroenterol 1951;18:243-56.

2. Horton JD, Hofmann LJ, Hetz SP. Presentation and management of Morgagni hernias in adults: A review of 298 cases. Surg Endosc 2008;22:1413-20.

3. Aghajanzadeh M, Khadem S, Khajeh Jahromi S, Gorabi HE, Ebrahimi H, Maafi AA. Clinical presentation and operative repair of Morgagni hernia. Interact Cardiovasc Thorac Surg 2012;15:608-11.

4. Kiliç D, Nadir A, Döner E, Kavukçu S, Akal M, Ozdemir $\mathrm{N}$, et al. Transthoracic approach in surgical management of Morgagni hernia. Eur J Cardiothorac Surg 2001;20:1016-9.

5. Moreaux J. Diaphragmatic hernias in adults. Rev Prat 1997;47:277-81.

6. Akamine S, Kawahara K, Nakamura A, Takahashi T, Yamamoto S, Ayabe H, et al. Successful utilization of a video-assisted thoracic approach to repair Morgagni's hernia: Report of a case. Surg Today 1995;25:654-6. 
7. Ulaş AB, Aydın Y, Eroğlu A. Laparoscopic approach in the treatment of Morgagni hernia. Turk Gogus Kalp Damar Cerrahisi Derg 2020;28:514-20.

8. Dapri G, Himpens J, Hainaux B, Roman A, Stevens E, Capelluto E, et al. Surgical technique and complications during laparoscopic repair of diaphragmatic hernias. Hernia 2007;11:179-83.

9. Park A, Doyle C. Laparoscopic Morgagni hernia repair: How I do it. J Gastrointest Surg 2014;18:1858-62.

10. Arikan S, Dogan MB, Kocakusak A, Ersoz F, Sari S, Duzkoylu Y, et al. Morgagni's hernia: Analysis of 21 patients with our clinical experience in diagnosis and treatment. Indian J Surg 2018;80:239-44.

11. Kurkcuoglu IC, Eroglu A, Karaoglanoglu N, Polat P, Balik AA, Tekinbas C. Diagnosis and surgical treatment of Morgagni hernia: report of three cases. Surg Today 2003;33:525-8.

12. Uygun I, Okur MH, Aydogdu B, Arslan MS, Cimen H, Otcu $\mathrm{S}$. Transumbilical scarless surgery with thoracic trocar: Easy and low-cost. J Korean Surg Soc 2013;84:360-6.

13. McBride CA, Beasley S. Re: Laparoscopic repair of diaphragmatic Morgagni hernia in children: Review of 3 cases. J Pediatr Surg 2011;46:1470.

14. Aydin Y, Altuntas B, Ulas AB, Daharli C, Eroglu A. Morgagni hernia: Transabdominal or transthoracic approach? Acta Chir Belg 2014;114:131-5.

15. Herman TE, Siegel MJ. Bilateral congenital Morgagni hernias. J Perinatol 2001;21:343-4.

16. Chang TH. Laparoscopic treatment of Morgagni-Larrey hernia. W V Med J 2004;100:14-7.

17. Tsimoyiannis EC, Tsimogiannis KE, PappasGogos G, Farantos C, Benetatos N, Mavridou P, et al.
Different pain scores in single transumbilical incision laparoscopic cholecystectomy versus classic laparoscopic cholecystectomy: A randomized controlled trial. Surg Endosc 2010;24:1842-8.

18. Kravetz AJ, Iddings D, Basson MD, Kia MA. The learning curve with single-port cholecystectomy. JSLS 2009;13:332-6.

19. Solomon D, Bell RL, Duffy AJ, Roberts KE. Single-port cholecystectomy: Small scar, short learning curve. Surg Endosc 2010;24:2954-7.

20. Diao M, Li L, Dong N, Li Q, Cheng W. Single-incision laparoscopic Roux-en-Y hepaticojejunostomy using conventional instruments for children with choledochal cysts. Surg Endosc 2012;26:1784-90.

21. Krpata DM, Ponsky TA. Instrumentation and equipment for single-site umbilical laparoscopic surgery. Semin Pediatr Surg 2011;20:190-5.

22. Orita M, Okino M, Yamashita K, Morita N, Esato K. Laparoscopic repair of a diaphragmatic hernia through the foramen of Morgagni. Surg Endosc 1997;11:668-70.

23. Akbiyik F, Tiryaki TH, Senel E, Mambet E, Livanelioğlu Z, Atayurt H. Is hernial sac removal necessary? Retrospective evaluation of eight patients with Morgagni hernia in 5 years. Pediatr Surg Int 2006;22:825-7.

24. Abraham V, Myla Y, Verghese S, Chandran BS. Morgagnilarrey hernia- a review of 20 cases. Indian J Surg 2012;74:391-5.

25. Palanivelu C, Rangarajan M, Rajapandian S, Amar V, Parthasarathi R. Laparoscopic repair of adult diaphragmatic hernias and eventration with primary sutured closure and prosthetic reinforcement: A retrospective study. Surg Endosc 2009;23:978-85. 